\title{
Cofactors As Metabolic Sensors Driving Cell Adaptation in Physiology and Disease
}

OPEN ACCESS

Edited by:

Lluis Fajas,

University of Lausanne,

Switzerland

Reviewed by:

Sana Siddiqui,

University of California, San

Francisco, United States

Roman L. Bogorad,

CRISPR Therapeutics, Inc.,

United States

*Correspondence:

Jean-Sébastien Annicotte jean-sebastien.annicotte@inserm.fr

tPresent address:

Nabil Rabhi,

Department of Biochemistry,

Boston University School of

Medicine, Boston, MA,

United States;

Sarah Anissa Hannou,

Division of Endocrinology and

Metabolism, Duke Molecular

Physiology Institute, Duke

University Medical Center,

Durham, NC, United States

Specialty section: This article was submitted to Cellular Endocrinology, a section of the journal

Frontiers in Endocrinology

Received: 31 July 2017

Accepted: 19 October 2017 Published: 03 November 2017

Citation:

Rabhi N, Hannou SA, Froguel P and Annicotte J-S (2017) Cofactors

As Metabolic Sensors Driving

Cell Adaptation in Physiology and Disease.

Front. Endocrinol. 8:304. doi: 10.3389/fendo.2017.00304

\author{
Nabil Rabhi ${ }^{1,2,3 \dagger}$, Sarah Anissa Hannou ${ }^{1,2,3 \dagger}$, Philippe Froguel ${ }^{1,2,3,4}$ \\ and Jean-Sébastien Annicotte ${ }^{1,2,3 *}$
}

\begin{abstract}
'Lille University, UMR 8199-EGID, Lille, France, ${ }^{2}$ CNRS, UMR 8199, Lille, France, ${ }^{3}$ Institut Pasteur de Lille, Lille, France, ${ }^{4}$ Department of Genomics of Common Disease, School of Public Health, Imperial College London, Hammersmith Hospital, London, United Kingdom
\end{abstract}

Chromatin architectures and epigenetic fingerprint regulation are fundamental for genetically determined biological processes. Chemical modifications of the chromatin template sensitize the genome to intracellular metabolism changes to set up diverse functional adaptive states. Accumulated evidence suggests that the action of epigenetic modifiers is sensitive to changes in dietary components and cellular metabolism intermediates, linking nutrition and energy metabolism to gene expression plasticity. Histone posttranslational modifications create a code that acts as a metabolic sensor, translating changes in metabolism into stable gene expression patterns. These observations support the notion that epigenetic reprograming-linked energy input is connected to the etiology of metabolic diseases and cancer. In the present review, we introduce the role of epigenetic cofactors and their relation with nutrient intake and we question the links between epigenetic regulation and the development of metabolic diseases.

Keywords: metabolism, nutritional status, cofactors, epigenetics, metabolites

\section{INTRODUCTION}

During their lifetime, cells receive several external signals, including hormones, growth factors, cytokines and other extracellular factors. Cells translate those signals to make crucial adaptive decisions, such as quiescence, proliferation, or differentiation. Recent works highlighted a fundamental role of environmental cues and nutrient availability in cell metabolism and adaptation. This flow of metabolites, through complex but well characterized metabolic networks, constitutes a fuel for diverse epigenetic cofactors thus relaying nutrition and diet changes into cytoplasmic signaling and chromatin remodeling.

Through their ability to sense internal and external cues, several transcriptional cofactors allow a cell to rapidly adapt by introducing reversible protein posttranslational modifications (PTMs). Hundreds of PTMs have been identified (1-3). However, only few have been directly linked to metabolic fluxes. PTMs include histone and non-histone modifications and represent a key physiological signal for cell adaptation (4-12). For the purposes of this review, we will only focus on PTMs linking changes in metabolism to histone modification.

Histone modifications-all with DNA methylation, RNA interference, and non-coding RNAencompassed by the term epigenetics represent diverted ways by which cells control the expression of genes without any alteration in the underlying genetic material. Since each cell has the same 
genetic code, epigenetic modifications allow a fine regulation of the gene expression and determine cell identities. Thereby, various chromatin modification patterns, such as acetylation, methylation, phosphorylation, $\mathrm{O}$-linked glycosylation, ubiquitination, and SUMOylation, result in a particular configuration that determines chromatin accessibility to the transcriptional machinery. For example, acetylation of lysine nine residues of histone H3 (H3K9), H3K14, and/or (mono-, di-, or tri) methylation of $\mathrm{H} 3 \mathrm{~K} 4, \mathrm{H} 3 \mathrm{~K} 36$ and $\mathrm{H} 3 \mathrm{~K} 79$ are often associated with transcriptionally active chromatin. By contrast, methylation of $\mathrm{H} 3 \mathrm{~K} 9, \mathrm{H} 3 \mathrm{~K} 27$, and $\mathrm{H} 4 \mathrm{~K} 20$ are markers of transcriptional silencing (13-15).

The generated metabolites remain the same for a given cell. Yet, the tissue function and nutriment availability will determine the metabolite requirements. Moreover, metabolic challenges, such as caloric or oxygen restriction or even a high-fat diet (16-19), will drive cell fate decisions. Consistent with this, dramatic epigenetic changes have been linked to metabolic disorders, such as obesity, insulin resistance, type-2 diabetes, and cancer (20-25). In this perspective, this review will focus on cofactor families linking nutritional input and metabolism to epigenetic pattern modifications.

\section{ACETYL-COA AND HISTONE/LYSINE ACETYLTRANSFERASE ENZYMES}

Lysine/Histone acetyltransferases (KAT/HAT) catalyze the transfer of an acetyl group from acetyl-CoA to $\varepsilon$-amino group of a histone lysine residue (26), which allows a transcriptional access to DNA by either neutralizing the positive histone charge, or serving as a binding site for chromatin remolding complexes. HAT can be divided on the basis of their subcellular localization or of the structural and functional similarity of their catalytic domains (27).

Acetyl-CoA availability is a major input for histone acetylation. A rise in acetyl-CoA level is sufficient to drive a yeast growth program by promoting histone acetylation at specific growth genes through the General control of amino acid synthesis protein 5-like 2 (GCN5, KAT2A) (28). In mammalian cells, histone acetylation with acetyl-CoA generated from glucose metabolism controls the early differentiation of embryonic stem cells (ESCs) (29). The limiting ATP citrate lyase enzyme that controls the conversion of citrate into oxaloacetate and acetyl-CoA was shown to be important for histone acetylation in response to glucose and growth factor stimulation (30).

As demonstrated for yeast, the mammalian GCN5 activity is required for histone acetylation during cell differentiation $(30,31)$. Tracing experiments using $13 \mathrm{C}$-carbon combined with acetyl-proteomics showed that up to $90 \%$ of histone acetylations on certain histone lysines are derived from fatty acid even in glucose excess. Acetyl-CoA generated from fatty acid $\beta$-oxidation seems to be important for the control of a gene expression program involved in lipid metabolism (32). Cytosolic acetate is another acetyl-CoA source that leads to an increase in $\mathrm{H} 3 \mathrm{~K}$, $\mathrm{H} 3 \mathrm{~K} 27$, and H3K56 histone acetylations of specific promoter regions, enhancing de novo lipid synthesis under hypoxic conditions (33). KAT2b is a KAT that acetylates H3K9 and H3K14.
During embryogenesis, GCN5 mRNA is already expressed at high levels by day 8 , whereas KAT2b mRNA is first detected on day 12.5 , suggesting that KAT2b and GCN5 play distinct roles by controlling the expression of a distinct set of genes (34). We have demonstrated that KAT2b is required for pancreatic $\beta$-cell adaptation to metabolic stress by promoting histone acetylation and gene expression of several unfolded protein response markers (35). While a $\beta$-cell-specific deletion of Kat $2 b$ in mouse has no effect under normal diet, Kat2b deficiency leads to a dramatic effect on $\beta$-cell morphology and function upon high fat feeding. KAT2b is thereby a major sensor of acetyl-CoA under hyperglycemic condition (35). Altogether, those data suggest that distinct histone acetyltransferases can sense acetylCoA upon different conditions and translate the appropriate cell response by activating different sets of genes. Moreover, the origin of acetyl-CoA seems to be important for this selectivity. Sutendra et al. recently demonstrated that acetyl-CoA is generated in the nucleus through a dynamic translocation of the mitochondrial pyruvate dehydrogenase complex (PDC), raising new questions about intracellular acetyl-CoA compartmentalization and the way its origin can regulate a specific set of genes (36-38). A better understanding of KAT activation, of the origin of acetyl-CoA and of its fluctuations within subcellular compartments upon different nutritional challenges can be of interest for the development of new therapeutic strategies against metabolic disease and cancer.

\section{NAD+-DEPENDENT AND INDEPENDENT HISTONE/LYSINE DEACETYLASES}

Lysine/Histone deacetylases (KDAC/HDAC) are the enzymes that catalyze the removal of the acetyl group from lysine residues of histones. On the basis of their mechanistic similarities, they can be divided into two groups: classical HDAC and $\mathrm{NAD}^{+}-$ dependent sirtuin deacetylase families $(39,40)$.

The mammalian $\mathrm{NAD}^{+}$-dependent KDACs consist of seven sirtuin members (SIRT1 to SIRT7), with distinct subcellular localizations. Three sirtuins are located in the mitochondria (SIRT3-SIRT5), while SIRT1, SIRT6, and SIRT7 are predominantly located in the nucleus, and SIRT2 is found in the cytoplasm $(41,42)$. $\mathrm{NAD}^{+}$levels rise in energy deficiency situations, such as exercise, caloric restriction, and fasting, leading to sirtuin activation $(43,44)$. In contrast, when energy is in excess, $\mathrm{NAD}^{+}$ is depleted, generating a higher $\mathrm{NAD}^{+} / \mathrm{NADH}$ ratio, which inhibits sirtuin activity $(6,41,42)$. This notion further argues toward a direct link between the nutritional status and epigenetic control.

SIRT1, one of the most studied KDAC, controls circadian rhythm and liver metabolism through the deacetylation of H3K9 and H3K14 at the promoter of clock genes $(45,46)$. Furthermore, through its interaction with Menin, SIRT1 enhances histone deacetylation and controls hepatic triglyceride accumulation $(47,48)$. SIRT1 can also deacetylate H4K16, functionally linking metabolic activity to genome stability and aging $(49,50)$. SIRT6, another nuclear sirtuin, is linked to aging by controlling a specific deacetylation of $\mathrm{H} 3 \mathrm{~K} 9$ at NF- $\mathrm{KB}$ target gene promoters (51). In cancer cells, SIRT7 is involved in the stabilization of their 
transformed phenotype by inducing the deacetylation of H3K18 at specific oncogene promoter regions (52).

The second families of KDAC are classical HDAC, and, in spite of their independent activity on endogenous metabolite, they have been linked to cellular metabolism. Shimazu et al. showed that $\beta$-hydroxybutyrate produced under fasting, starvation or intense exercise condition is a natural endogenous HDAC inhibitor leading to increased H3K9 and H3K4 acetylation $(18,53)$. It also increases histone acetylation at the Foxo3a and Mt2 promoters through the inhibition of HDAC1 and HDAC2 (18).

Lactate production, as a result of an increased rate of glycolysis, has also been shown to upregulate the expression of genes associated with HDAC proteins (54). The authors have demonstrated that the primary effect of lactate on gene expression depends on HDAC inhibition (54). Therefore, lactate may be an important transcriptional regulator, linking the metabolic state of the cell to gene transcription. Further work is needed to corroborate whether the lactate produced in vivo has a tissue specific effect on HDAC cofactors. Moreover, lactate has been implicated in the modulation of the DNA damage and repair processes as well as in the resistance of carcinoma cells to anticancer therapy (55).

Altogether, those data provide evidence for a direct link between metabolism products and cellular adaptation through the modulation of KDAC activity.

\section{HISTONE METHYLATION AND S-ADENOSYLMETHIONINE (SAM)}

S-adenosylmethionine, generated by the methionine cycle, contains the active methyl donor group used by methyltransferases to methylate RNA, DNA, and proteins, including histones (56-61). While extensive studies focused on the changes of methylation status upon embryonic development, physiology, and diseases, the link between intracellular SAM fluctuation and their conversion into specific epigenetic modifications remains poorly understood. For instance, only histone methylation has been linked to methionine availability, an essential amino acid obtained from the diet (62).

Histone methylation can occur on arginine or lysine residues. While lysine can be mono-, di-, or trimethylated, arginine can only be mono-methylated. There are three classes of histone methyltransferase: SET domain lysine methyltransferases, nonSET domain lysine methyltransferases (disruptor of telomeric silencing 1-like, DOT1L), and arginine methyltransferases (PRMT) (63-65).

In mouse ESCs, mitochondrial threonine dehydrogenase $(\mathrm{TDH})$, an enzyme that catabolizes threonine into glycine and acetyl-CoA, has been shown to be important in maintaining the intracellular SAM level (66). Threonine depletion in culture medium or TDH knockdown in mouse ESCs decreases SAM accumulation and H3K4me3 mark, whereas no effect was observed in other methylation marks (66). In cancer cells, an aberrant expression of Nicotinamide N-methyltransferase-a limiting enzyme that metabolizes SAM-exerts specific control over the cells methylation potential (67). Moreover, recent works provide evidence in both mouse and human that methionine status is sufficient for the control of numerous physiological processes including the activity of genes involved in cell fate through the modulation of histone methylation levels (62).

As observed for HDAC, PMRT activity can be controlled by intermediary metabolites. Three recent reports showed that an increased intracellular concentration of methylthioadenosine (MTA) in cancer cells harboring 5-methylthioadenosine phosphorylase (MTAP) deletions leads to PMRT5 inhibition (68-70). MTAP is the enzyme controlling MTA cleavage to generate precursor substrates for methionine and adenine salvage pathways. In cancer cells, MTAP deficiency leads to partial metabolitebased inhibition of PRMT5 by altering the ratio of MTA to SAM, which results in a decreased H4R3me2s mark (68-70). More studies are needed to understand whether the MTA-toSAM ratio can also be controlled by physiological metabolic nutritional states.

\section{FLAVIN ADENINE DINUCLEOTIDE (FAD) AND HISTONE DEMETHYLASES}

Histone methylation was originally considered as a permanent chromatin alteration until the landmark discovery of histone lysine-specific demethylase 1 (LSD1) by Shi Yang's group, established both in vitro and in vivo methylation reversibility (71). LSD1 uses FAD formed from ATP and riboflavin (vitamin B2) in mitochondria as a cofactor to demethylate mono- and di-methylated H3K4 and H3K9 $(72,73)$. Although LSD1 demethylase activity appears to control the metabolism in favor of de novo fatty acid synthesis over gluconeogenesis in hepatocyte and brown adipose tissue thermogenic activity, a direct link between nutritional status and LSD1 activity still needs to be established (74-78). For instance, recent works demonstrate that livers from mouse fed with folate-deficient diet present an increased dimethyl-H3K4 and decreased LSD1 activity (79). More studies are needed to decipher the metabolic consequence of FAD fluctuation upon physiological and pathophysiological conditions.

\section{$\alpha$-KETOGLUTARATE ( $\alpha$ KG) AND HISTONE DEMETHYLASES}

$\alpha$-ketoglutarate is produced from isocitrate through the activity of two key-enzymes of the Krebs cycle, isocitrate dehydrogenase 1 and 2 (IDH 1 and IDH2) $(16,80)$. $\alpha$ KG can also be produced anaplerotically from glutamate by oxidative deamination, using glutamate dehydrogenase (49). Under fasting or caloric restriction, the accumulation of $\alpha \mathrm{KG}$ is used by the $\alpha \mathrm{KG}$-depending dioxygenase to influence the epigenetic status of the cells $(81,82)$. Several chromatin-modifying enzymes are regulated by $\alpha \mathrm{KG}$ availability, including demethylase enzymes containing a Jumonji $\mathrm{C}$ domain $(\mathrm{JmjC})$ and ten-eleven translocation (TET) protein families (83-86).

The JmjC subfamily comprises the largest identified family of lysine demethylases (KDMs) with more than 60 enzymes identified in humans (87). In addition to $\alpha \mathrm{KG}$, JmjC-dependent histone demethylation requires iron $\mathrm{Fe}(\mathrm{II})$ (88). Each JmjC 
family member exhibits preference to reverse lysine or arginine trimethylated histone. Considering the key-determinant role of methylation on gene expression and demethylase specificity, KDM2 and KDM5 families have been shown to promote a repression chromatin status, while KDM3, KDM6 and KDM7 act as chromatin activators (63).

Ten-eleven translocation protein family can catalyze 5 -methylcytosine $(5 \mathrm{mC})$ to 5 -hydroxymethylcytosine $(5 \mathrm{hmC})$, 5 -formylcytosine $(5 \mathrm{fC})$ and 5-carboxylcytosine $(5 \mathrm{caC})$ in three consecutive Fe(II)- and 2-oxoglutarate (2-OG)-dependent oxidation reactions $(89,90)$. Gene expression depends on the location of the $5 \mathrm{hmC}$ marks. Indeed, the presence of $5 \mathrm{hmC}$ in the gene bodies was found to correlate positively with gene expression, whereas no correlation with gene expression was found when $5 \mathrm{hmC}$ peaks are located at transcription start sites $(91,92)$.

$\alpha$-ketoglutarate can be derived from glucose and glutamine. However, few studies have demonstrated a direct link between $\alpha \mathrm{KG}$ generation and histone demethylation. A direct manipulation of intracellular $\alpha \mathrm{KG} /$ succinate ratio is sufficient to regulate chromatin state in ESCs. The accumulation of $\alpha \mathrm{KG}$ promotes self-renewal of ESCs through JMJD3 and Tet1/Tet2 demethylation of $\mathrm{H} 3 \mathrm{~K} 9 \mathrm{me} 3, \mathrm{H} 3 \mathrm{~K} 27 \mathrm{me} 3$, and $\mathrm{H} 4 \mathrm{~K} 20 \mathrm{me}$ histone marks (93). Gas chromatography coupled to mass spectrometry analysis revealed a rapid increase in hepatic $\alpha-K G$ levels following intraperitoneal glucose injection in mice. Strikingly, $5 \mathrm{hmC}$ and $5 \mathrm{fC}$ marks are reported to increase in various mouse tissues including the liver, kidney, and muscle without any change in TET protein expression or localization leading to a change in gene expression (94). Changes in demethylase activity may thereby contribute to cellular and tissue dysfunction under persistent hyperglycemic conditions.

In cancer cells, a loss of function mutation of TCA cycle enzymes, such as mitochondrial succinate dehydrogenase or fumarate hydratase, promotes succinate and fumarate abundance $(95,96)$. Both metabolites inhibit $\alpha$-KG-depending demethylase leading to a decreased $5 \mathrm{hmC}$ mark and a specific increase in H3K9me3 levels $(96,97)$. Somatic mutations of IDH1 and IDH2 have been identified in glioblastomas, acute myelogenous leukemia, chondrosarcomas and lymphomas and other solid tumors (98-103). These gain-of-function mutations lead to a new enzymatic activity promoting the conversion of $\alpha-K G$ to produce $\mathrm{D}(\mathrm{R})$-2-hydroxyglutarate (R2HG) $(104,105)$. This oncometabolite, which accumulates in tumors with IDH mutations, is a competitive inhibitor of TET and JmjC protein family activity (106-109).

Two recent reports describe another metabolite generated under hypoxic condition by the conversion of $\alpha-\mathrm{KG}$ to produce L(S)-2-hydroxyglutarate (S2HG) $(110,111)$. Both reports demonstrate that S2HG is the product of malate dehydrogenase 1, malate dehydrogenase 2 , and lactate dehydrogenase A. The accumulation of this metabolite leads to $\alpha$-KG-depending demethylase activity inhibition toward TET1/2 and $\operatorname{KDM} 4 \mathrm{C}(110,111)$. Interestingly, this effect is not cancer-specific since a similar level of S2HG production was observed in endothelial cells (110). Moreover, manipulating S2HG is sufficient to increase the methylation of histone repressive marks, suggesting that this metabolite may be generated in other conditions than hypoxia.
Further studies are needed to understand the role of S2HG in controlling proliferation versus fate in ES cell.

\section{NUCLEAR LOCALIZATION OF METABOLITES}

The cytosol and nucleus are dense and very viscous. This may restrict the diffusion of small molecules and slow down biochemical reactions. Moreover, several metabolite pathways are organized in multiprotein complexes to allow reaction channeling to facilitate signaling. A multiprotein complex (molecular assembly line) has been proposed to promote efficient substrate channeling from one enzyme to the next (112). Accumulated evidence suggests a close coupling of the histone-modifying enzymes with their critical cofactor synthesis enzyme in the nucleus. Their nuclear translocation aims to provide in situ metabolite synthesis in response to metabolic stress. For example, Katoh and colleagues demonstrate that the SAM-generating enzyme, methionine adenosyltransferase II (MATII $\alpha)$, is localized in the nucleus and interacts with the Swi/Snf and NuRD complexes, supplying SAM for methyltransferases (113). MATII $\alpha$ will maintain a local high SAM concentration, which is used by an $\mathrm{H} 3 \mathrm{~K} 9$-specific histone methyltransferase to repress the oncogene MafK transcriptional activity (113).

Similarly, a pyruvate conversion to acetyl-CoA is processed in the nucleus through the nuclear translocation of the mitochondrial PDC. Nuclear PDC levels, as well as the histone H3 and $\mathrm{H} 4$ global acetylation levels, increase in a cell-cycle depending manner upon epidermal growth factor, serum, or mitochondrial stress (36). Nuclear PDC inhibition leads to a specific decrease in the acetylation of the histone that is important for the gene expression of G1-S phase progression and S phase markers (36). Moreover, nuclear concentration of acetyl-coA has been shown to be important for osteoblast differentiation (114). In line with this, recent works showed that pyruvate is critical for the TCA cycle enzyme nuclear localization in mammalian zygotic genome activation (115). The authors demonstrated that nutrients, such as pyruvate, are essential for an early pre-implantation development in mouse and human. Mechanistically, Nagaraj and colleagues showed that pyruvate controls the nuclear localization of multiple TCA enzymes in addition to proteins related to TCA cycle entry, including pyruvate carboxylase, pyruvate dehydrogenase, pyruvate dehydrogenase phosphatase, citrate synthase, aconitase-2, and isocitrate dehydrogenase 3A (115). Moreover, acetate-dependent acetyl-coA synthase 2 (ACSS2) binds to chromatin nearby regions of genes that are upregulated during neuron differentiation. A decrease in ACSS2 lowers nuclear acetyl-coA levels, histone acetylation, and neuronal genes in hippocampus, leading to defective spatial memory (116). Those data support a critical role of ACSS2, linking acetate metabolism to localized acetyl-coA production, histone acetylation, and gene expression. In hepatocellular carcinoma cells, the nuclear localization of ACCS2 promotes cancer cell survival by increasing $\mathrm{H} 3 \mathrm{~K} 9, \mathrm{H} 3 \mathrm{~K} 27$, and $\mathrm{H} 3 \mathrm{~K} 56$ acetylation levels at the promoter regions of lipogenic genes such as acetylCoA carboxylase alpha and fatty acid synthase and enhances de novo lipid synthesis (33). 
Finally, $\mathrm{NAD}^{+}$, the critical cofactor of sirtuin deacetylase, can also be generated in the nucleus through the conversion of nicotinamide by nuclear NMNAT1. NMNAT1 enzymatic activity is required to provide $\mathrm{NAD}^{+}$for SIRT1 (117) and PARP1 (118) during transcriptional regulation and DNA repair.

The precise nuclear localization of critical cofactor-generating enzymes supports the presence of localized subdomains within the chromatin that may promote the clustering of relevant PTMs at specific genomic loci. This model raises a new question on how the nutritional state and metabolism products control the nuclear localization and activity of those microdomains. The second question is to know whether those processes are tissue and cell specific and if they are disturbed under pathophysiological conditions such as obesity or cancer. Then, the final question is: what is the functional and physiological significance of this process?

\section{CONCLUSION}

Scientific evidence clearly supports that nutrition and diet are the most influential lifestyle factors that contribute to health and the development and progression of chronic diseases, including metabolic disorders, neurodegenerative diseases, cancers, and cardiovascular diseases.
The recent exciting advances surveyed herein show that eating habits and nutritional input is deciphered by a metabolic sensor and translated into an adaptive epigenetic code that controls major biological processes such as cell survival, proliferation, DNA damage, and cellular energy production and/or storage (Figure 1). The next major challenge for epigenetic research will depend on the ability to translate the lessons learned from epigenomic profiling, structural studies, and regulatory mechanisms to treatment.

However, it will also be important to strengthen our understanding on how metabolite fluctuations can control a specific gene set in a given tissue. Importantly, it will be of interest to understand how all those pathways integrate into a specific physiological and/or pathophysiological state. The mechanisms controlling the concentration of metabolites in microdomains within the nucleus and the ability for this chromatin compartmentalization of critical cofactor synthesis enzyme to coordinate specific responses to metabolite changes are two other intriguing questions.

Finally, the most important question might be to determine whether cofactors can be successful targets for metabolic diseases. Although this review highlights how far we have come in less than two decades, those findings shed light on a wide

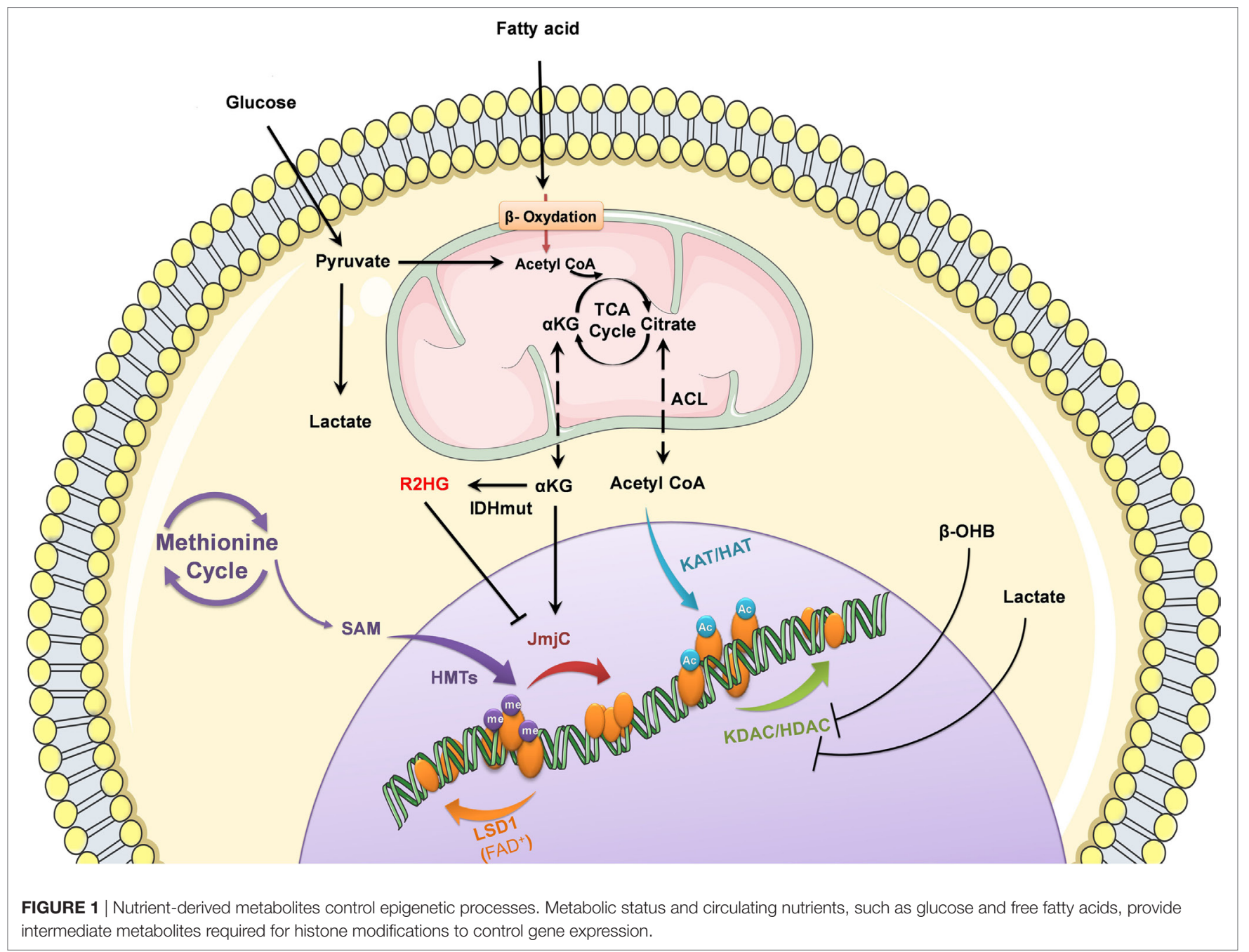


range of more open questions to understand the role of cofactors in nutritional sensing and the epigenetic control of gene expression.

\section{AUTHOR CONTRIBUTIONS}

NR, SAH, J-SA, and PF discussed and wrote the manuscript.

\section{FUNDING}

The authors thank members of the CNRS UMR 8199 for helpful discussions. The authors acknowledge Estelle Le Borgne

\section{REFERENCES}

1. Walsh CT, Garneau-Tsodikova S, Gatto GJ. Protein posttranslational modifications: the chemistry of proteome diversifications. Angew Chem Int Ed Engl (2005) 44:7342-72. doi:10.1002/anie.200501023

2. Jensen $\mathrm{ON}$. Interpreting the protein language using proteomics. Nat Rev Mol Cell Biol (2006) 7:391-403. doi:10.1038/nrm1939

3. Janssen KA, Sidoli S, Garcia BA. Recent achievements in characterizing the histone code and approaches to integrating epigenomics and systems biology. Methods Enzymol (2017) 586:359-78. doi:10.1016/bs.mie.2016. 10.021

4. Menzies KJ, Zhang H, Katsyuba E, Auwerx J. Protein acetylation in metabolism - metabolites and cofactors. Nat Rev Endocrinol (2016) 12:43-60. doi:10.1038/nrendo.2015.181

5. Choudhary C, Weinert BT, Nishida Y, Verdin E, Mann M. The growing landscape of lysine acetylation links metabolism and cell signalling. Nat Rev Mol Cell Biol (2014) 15:536-50. doi:10.1038/nrm3841

6. Gao AW, Cantó C, Houtkooper RH. Mitochondrial response to nutrient availability and its role in metabolic disease. EMBO Mol Med (2014) 6:580-9. doi:10.1002/emmm.201303782

7. Matilainen O, Quirós PM, Auwerx J. Mitochondria and epigenetics crosstalk in homeostasis and stress. Trends Cell Biol (2017) 27:453-63. doi:10.1016/j.tcb.2017.02.004

8. Katada S, Imhof A, Sassone-Corsi P. Connecting threads: epigenetics and metabolism. Cell (2012) 148:24-8. doi:10.1016/j.cell.2012.01.001

9. Su X, Wellen KE, Rabinowitz JD. Metabolic control of methylation and acetylation. Curr Opin Chem Biol (2016) 30:52-60. doi:10.1016/j.cbpa.2015. 10.030

10. Öst A, Pospisilik JA. Epigenetic modulation of metabolic decisions. Curr Opin Cell Biol (2015) 33:88-94. doi:10.1016/j.ceb.2014.12.005

11. Kaelin WG, McKnight SL. Influence of metabolism on epigenetics and disease. Cell (2013) 153:56-69. doi:10.1016/j.cell.2013.03.004

12. Rodriguez H, Rafehi H, Bhave M, El-Osta A. Metabolism and chromatin dynamics in health and disease. Mol Aspects Med (2017) 54:1-15. doi:10.1016/j.mam.2016.09.004

13. Goldberg AD, Allis CD, Bernstein E. Epigenetics: a landscape takes shape. Cell (2007) 128:635-8. doi:10.1016/j.cell.2007.02.006

14. Zhang $\mathrm{T}$, Cooper S, Brockdorff N. The interplay of histone modifications - writers that read. EMBO Rep (2015) 16:1467-81. doi:10.15252/ embr.201540945

15. Allis CD, Jenuwein T. The molecular hallmarks of epigenetic control. Nat Rev Genet (2016) 17:487-500. doi:10.1038/nrg.2016.59

16. Kouzarides T. Chromatin modifications and their function. Cell (2007) 128:693-705. doi:10.1016/j.cell.2007.02.005

17. Michan S. Calorie restriction and NAD+/sirtuin counteract the hallmarks of aging. Front Biosci (Landmark Ed) (2014) 19:1300-19. doi:10.2741/4283

18. Shimazu T, Hirschey MD, Newman J, He W, Shirakawa K, Le Moan N, et al. Suppression of oxidative stress by $\beta$-hydroxybutyrate, an endogenous histone deacetylase inhibitor. Science (2013) 339:211-4. doi:10.1126/ science. 1227166

19. Boutant $M$, Cantó C. SIRT1 metabolic actions: integrating recent advances from mouse models. Mol Metab (2014) 3:5-18. doi:10.1016/j. molmet.2013.10.006 for help with illustration. This work was supported by grants from «European Genomic Institute for Diabetes» (E.G.I.D, ANR-10-LABX-46 to PF and J-SA), ANR Equipex 2010 (ANR10-EQPX-07-01; 'LIGAN-PM' Genomics platform), European Commission, European Research Council (GEPIDIAB 294785 to PF), INSERM, CNRS, Association pour la Recherche sur le Diabète (to J-SA), Lille2 University (to NR and J-SA), Conseil Régional Hauts de France and Métropole Européenne de Lille (to NR and J-SA), F.E.D.E.R. (Fonds Européen de Développement Régional, to NR, PF, J-SA), European Foundation for the Study of Diabetes (EFSD, to J-SA) and Société Francophone du Diabète (to SAH and J-SA).

20. Bell CG. The epigenomic analysis of human obesity. Obesity (Silver Spring) (2017) 25:1471-81. doi:10.1002/oby.21909

21. Park J-H, Kim S-H, Lee MS, Kim M-S. Epigenetic modification by dietary factors: implications in metabolic syndrome. Mol Aspects Med (2017) 54:58-70. doi:10.1016/j.mam.2017.01.008

22. Ling C, Groop L. Epigenetics: a molecular link between environmental factors and type 2 diabetes. Diabetes (2009) 58:2718-25. doi:10.2337/ $\mathrm{db} 09-1003$

23. Sterns JD, Smith CB, Steele JR, Stevenson KL, Gallicano GI. Epigenetics and type II diabetes mellitus: underlying mechanisms of prenatal predisposition. Front Cell Dev Biol (2014) 2:15. doi:10.3389/fcell.2014.00015

24. Sharma S, Kelly TK, Jones PA. Epigenetics in cancer. Carcinogenesis (2010) 31:27-36. doi:10.1093/carcin/bgp220

25. Rodríguez-Paredes M, Esteller M. Cancer epigenetics reaches mainstream oncology. Nat Med (2011) 17:330-9. doi:10.1038/nm.2305

26. Hirsch CL, Wrana JL, Dent SYR. KATapulting toward pluripotency and cancer. J Mol Biol (2017) 429:1958-77. doi:10.1016/j.jmb.2016.09.023

27. Wapenaar H, Dekker FJ. Histone acetyltransferases: challenges in targeting bi-substrate enzymes. Clin Epigenetics (2016) 8:59. doi:10.1186/ s13148-016-0225-2

28. Cai L, Sutter BM, Li B, Tu BP. Acetyl-CoA induces cell growth and proliferation by promoting the acetylation of histones at growth genes. Mol Cell (2011) 42:426-37. doi:10.1016/j.molcel.2011.05.004

29. Moussaieff A, Rouleau M, Kitsberg D, Cohen M, Levy G, Barasch D, et al. Glycolysis-mediated changes in acetyl-CoA and histone acetylation control the early differentiation of embryonic stem cells. Cell Metab (2015) 21:392-402. doi:10.1016/j.cmet.2015.02.002

30. Wellen KE, Hatzivassiliou G, Sachdeva UM, Bui TV, Cross JR, Thompson CB. ATP-citrate lyase links cellular metabolism to histone acetylation. Science (2009) 324:1076-80. doi:10.1126/science.1164097

31. Wang L, Dent SYR. Functions of SAGA in development and disease. Epigenomics (2014) 6:329-39. doi:10.2217/epi.14.22

32. McDonnell E, Crown SB, Fox DB, Kitir B, Ilkayeva OR, Olsen CA, et al. Lipids reprogram metabolism to become a major carbon source for histone acetylation. Cell Rep (2016) 17:1463-72. doi:10.1016/j.celrep.2016.10.012

33. Gao X, Lin S-H, Ren F, Li J-T, Chen J-J, Yao C-B, et al. Acetate functions as an epigenetic metabolite to promote lipid synthesis under hypoxia Nat Commun (2016) 7:11960. doi:10.1038/ncomms11960

34. Yamauchi T, Yamauchi J, Kuwata T, Tamura T, Yamashita T, Bae N, et al. Distinct but overlapping roles of histone acetylase PCAF and of the closely related PCAF-B/GCN5 in mouse embryogenesis. Proc Natl Acad Sci U S A (2000) 97:11303-6. doi:10.1073/pnas.97.21.11303

35. Rabhi N, Denechaud P-D, Gromada X, Hannou SA, Zhang H, Rashid T, et al. KAT2B is required for pancreatic beta cell adaptation to metabolic stress by controlling the unfolded protein response. Cell Rep (2016) 15:1051-61. doi:10.1016/j.celrep.2016.03.079

36. Sutendra G, Kinnaird A, Dromparis P, Paulin R, Stenson TH, Haromy A, et al. A nuclear pyruvate dehydrogenase complex is important for the generation of acetyl-CoA and histone acetylation. Cell (2014) 158:84-97. doi:10.1016/j.cell.2014.04.046

37. Shi L, Tu BP. Acetyl-CoA and the regulation of metabolism: mechanisms and consequences. Curr Opin Cell Biol (2015) 33:125-31. doi:10.1016/j. ceb.2015.02.003 
38. Boukouris AE, Zervopoulos SD, Michelakis ED. Metabolic enzymes moonlighting in the nucleus: metabolic regulation of gene transcription. Trends Biochem Sci (2016) 41:712-30. doi:10.1016/j.tibs.2016.05.013

39. Yoshida M, Kudo N, Kosono S, Ito A. Chemical and structural biology of protein lysine deacetylases. Proc Jpn Acad Ser B Phys Biol Sci (2017) 93:297-321. doi:10.2183/pjab.93.019

40. Haberland M, Montgomery RL, Olson EN. The many roles of histone deacetylases in development and physiology: implications for disease and therapy. Nat Rev Genet (2009) 10:32-42. doi:10.1038/nrg2485

41. Imai S, Guarente L. Ten years of NAD-dependent SIR2 family deacetylases: implications for metabolic diseases. Trends Pharmacol Sci (2010) 31:212-20. doi:10.1016/j.tips.2010.02.003

42. Cantó C, Menzies KJ, Auwerx J. NAD(+) metabolism and the control of energy homeostasis: a balancing act between mitochondria and the nucleus. Cell Metab (2015) 22:31-53. doi:10.1016/j.cmet.2015.05.023

43. White AT, Schenk S. NAD(+)/NADH and skeletal muscle mitochondrial adaptations to exercise. Am J Physiol Endocrinol Metab (2012) 303:E308-21. doi:10.1152/ajpendo.00054.2012

44. Moreno CL, Mobbs CV. Epigenetic mechanisms underlying lifespan and age-related effects of dietary restriction and the ketogenic diet. Mol Cell Endocrinol (2016) 455:33-40. doi:10.1016/j.mce.2016.11.013

45. Nakahata Y, Kaluzova M, Grimaldi B, Sahar S, Hirayama J, Chen D, et al. The NAD+-dependent deacetylase SIRT1 modulates CLOCK-mediated chromatin remodeling and circadian control. Cell (2008) 134:329-40. doi:10.1016/j.cell.2008.07.002

46. Masri S, Sassone-Corsi P. Sirtuins and the circadian clock: bridging chromatin and metabolism. Sci Signal (2014) 7:re6. doi:10.1126/scisignal. 2005685

47. Cao Y, Xue Y, Xue L, Jiang X, Wang X, Zhang Z, et al. Hepatic menin recruits SIRT1 to control liver steatosis through histone deacetylation. J Hepatol (2013) 59:1299-306. doi:10.1016/j.jhep.2013.07.011

48. Cheng J, Liu C, Hu K, Greenberg A, Wu D, Ausman LM, et al. Ablation of systemic SIRT1 activity promotes nonalcoholic fatty liver disease by affecting liver-mesenteric adipose tissue fatty acid mobilization. Biochim Biophys Acta (2017) 1863(11):2783-90. doi:10.1016/j.bbadis.2017.08.004

49. Dang W, Steffen KK, Perry R, Dorsey JA, Johnson FB, Shilatifard A, et al. Histone H4 lysine 16 acetylation regulates cellular lifespan. Nature (2009) 459:802-7. doi:10.1038/nature08085

50. Saunders LR, Verdin E. Sirtuins: critical regulators at the crossroads between cancer and aging. Oncogene (2007) 26:5489-504. doi:10.1038/sj.onc. 1210616

51. Kawahara TLA, Michishita E, Adler AS, Damian M, Berber E, Lin M, et al. SIRT6 links histone $\mathrm{H} 3$ lysine 9 deacetylation to NF-kappaB-dependent gene expression and organismal life span. Cell (2009) 136:62-74. doi:10.1016/j. cell.2008.10.052

52. Barber MF, Michishita-Kioi E, Xi Y, Tasselli L, Kioi M, Moqtaderi Z, et al. SIRT7 links H3K18 deacetylation to maintenance of oncogenic transformation. Nature (2012) 487:114-8. doi:10.1038/nature11043

53. Newman JC, Verdin E. Ketone bodies as signaling metabolites. Trends Endocrinol Metab (2014) 25:42-52. doi:10.1016/j.tem.2013.09.002

54. Latham T, Mackay L, Sproul D, Karim M, Culley J, Harrison DJ, et al. Lactate, a product of glycolytic metabolism, inhibits histone deacetylase activity and promotes changes in gene expression. Nucleic Acids Res (2012) 40:4794-803. doi:10.1093/nar/gks066

55. Wagner W, Ciszewski WM, Kania KD. L- and D-lactate enhance DNA repair and modulate the resistance of cervical carcinoma cells to anticancer drugs via histone deacetylase inhibition and hydroxycarboxylic acid receptor 1 activation. Cell Commun Signal (2015) 13:36. doi:10.1186/s12964-015-0114-x

56. Finkelstein JD. Methionine metabolism in mammals. J Nutr Biochem (1990) 1:228-37. doi:10.1016/0955-2863(90)90070-2

57. Motorin Y, Helm M. RNA nucleotide methylation. Wiley Interdiscip Rev RNA (2011) 2:611-31. doi:10.1002/wrna.79

58. Schübeler D. Function and information content of DNA methylation. Nature (2015) 517:321-6. doi:10.1038/nature14192

59. Greer EL, Shi Y. Histone methylation: a dynamic mark in health, disease and inheritance. Nat Rev Genet (2012) 13:343-57. doi:10.1038/nrg3173

60. Mentch SJ, Locasale JW. One-carbon metabolism and epigenetics: understanding the specificity. Ann N Y Acad Sci (2016) 1363:91-8. doi:10.1111/ nyas. 12956
61. Zhou S, Alkhalaf LM, de Los Santos EL, Challis GL. Mechanistic insights into class B radical-S-adenosylmethionine methylases: ubiquitous tailoring enzymes in natural product biosynthesis. Curr Opin Chem Biol (2016) 35:73-9. doi:10.1016/j.cbpa.2016.08.021

62. Mentch SJ, Mehrmohamadi M, Huang L, Liu X, Gupta D, Mattocks D, et al. Histone methylation dynamics and gene regulation occur through the sensing of one-carbon metabolism. Cell Metab (2015) 22:861-73. doi:10.1016/j.cmet.2015.08.024

63. Black JC, Van Rechem C, Whetstine JR. Histone lysine methylation dynamics: establishment, regulation, and biological impact. Mol Cell (2012) 48:491-507. doi:10.1016/j.molcel.2012.11.006

64. Alam H, Gu B, Lee MG. Histone methylation modifiers in cellular signaling pathways. Cell Mol Life Sci (2015) 72:4577-92. doi:10.1007/s00018015-2023-y

65. Ng SS, Yue WW, Oppermann U, Klose RJ. Dynamic protein methylation in chromatin biology. Cell Mol Life Sci (2009) 66:407-22. doi:10.1007/ s00018-008-8303-z

66. Shyh-Chang N, Locasale JW, Lyssiotis CA, Zheng Y, Teo RY, Ratanasirintrawoot $\mathrm{S}$, et al. Influence of threonine metabolism on S-adenosylmethionine and histone methylation. Science (2013) 339:222-6. doi:10.1126/science. 1226603

67. Ulanovskaya OA, Zuhl AM, Cravatt BF. NNMT promotes epigenetic remodeling in cancer by creating a metabolic methylation sink. Nat Chem Biol (2013) 9:300-6. doi:10.1038/nchembio.1204

68. Kryukov GV, Wilson FH, Ruth JR, Paulk J, Tsherniak A, Marlow SE, et al. MTAP deletion confers enhanced dependency on the PRMT5 arginine methyltransferase in cancer cells. Science (2016) 351:1214-8. doi:10.1126/ science.aad5214

69. Mavrakis KJ, McDonald ER, Schlabach MR, Billy E, Hoffman GR, deWeck A, et al. Disordered methionine metabolism in MTAP/CDKN2Adeleted cancers leads to dependence on PRMT5. Science (2016) 351:1208-13. doi:10.1126/science.aad5944

70. Marjon K, Cameron MJ, Quang P, Clasquin MF, Mandley E, Kunii K, et al. MTAP deletions in cancer create vulnerability to targeting of the MAT2A/PRMT5/RIOK1 axis. Cell Rep (2016) 15:574-87. doi:10.1016/j. celrep.2016.03.043

71. Shi Y, Lan F, Matson C, Mulligan P, Whetstine JR, Cole PA, et al. Histone demethylation mediated by the nuclear amine oxidase homolog LSD1. Cell (2004) 119:941-53. doi:10.1016/j.cell.2004.12.012

72. Zheng Y-C, Ma J, Wang Z, Li J, Jiang B, Zhou W, et al. A systematic review of histone lysine-specific demethylase 1 and its inhibitors. Med Res Rev (2015) 35:1032-71. doi:10.1002/med.21350

73. Hino S, Sakamoto A, Nagaoka K, Anan K, Wang Y, Mimasu S, et al. FAD-dependent lysine-specific demethylase-1 regulates cellular energy expenditure. Nat Commun (2012) 3:758. doi:10.1038/ncomms1755

74. Abdulla A, Zhang Y, Hsu F-N, Xiaoli AM, Zhao X, Yang EST, et al. Regulation of lipogenic gene expression by lysine-specific histone demethylase-1 (LSD1). J Biol Chem (2014) 289:29937-47. doi:10.1074/jbc.M114.573659

75. Pan D, Mao C, Wang Y-X. Suppression of gluconeogenic gene expression by LSD1-mediated histone demethylation. PLoS One (2013) 8:e66294. doi:10.1371/journal.pone.0066294

76. Duteil D, Tosic M, Lausecker F, Nenseth HZ, Müller JM, Urban S, et al. Lsd1 ablation triggers metabolic reprogramming of brown adipose tissue. Cell Rep (2016) 17:1008-21. doi:10.1016/j.celrep.2016.09.053

77. Zeng X, Jedrychowski MP, Chen Y, Serag S, Lavery GG, Gygi SP, et al. Lysine-specific demethylase 1 promotes brown adipose tissue thermogenesis via repressing glucocorticoid activation. Genes Dev (2016) 30:1822-36. doi:10.1101/gad.285312.116

78. Lin JZ, Farmer SR. LSD1-a pivotal epigenetic regulator of brown and beige fat differentiation and homeostasis. Genes Dev (2016) 30:1793-5. doi:10.1101/gad.288720.116

79. Garcia BA, Luka Z, Loukachevitch LV, Bhanu NV, Wagner C. Folate deficiency affects histone methylation. Med Hypotheses (2016) 88:63-7. doi:10.1016/j. mehy.2015.12.027

80. Berger SL, Sassone-Corsi P. Metabolic signaling to chromatin. Cold Spring Harb Perspect Biol (2016) 8:a019463. doi:10.1101/cshperspect.a019463

81. Tanaka Y, Okamoto K, Teye K, Umata T, Yamagiwa N, Suto Y, et al. JmjC enzyme KDM2A is a regulator of rRNA transcription in response to starvation. EMBO J (2010) 29:1510-22. doi:10.1038/emboj.2010.56 
82. Hagopian K, Ramsey JJ, Weindruch R. Krebs cycle enzymes from livers of old mice are differentially regulated by caloric restriction. Exp Gerontol (2004) 39:1145-54. doi:10.1016/j.exger.2004.04.009

83. Teperino R, Schoonjans K, Auwerx J. Histone methyl transferases and demethylases; can they link metabolism and transcription? Cell Metab (2010) 12:321-7. doi:10.1016/j.cmet.2010.09.004

84. Shen L, Zhang Y. Enzymatic analysis of Tet proteins: key enzymes in the metabolism of DNA methylation. Methods Enzymol (2012) 512:93-105. doi:10.1016/B978-0-12-391940-3.00005-6

85. Markolovic S, Wilkins SE, Schofield CJ. Protein hydroxylation catalyzed by 2-oxoglutarate-dependent oxygenases. J Biol Chem (2015) 290:20712-22. doi:10.1074/jbc.R115.662627

86. Li F, Xu W, Zhao S. Regulatory roles of metabolites in cell signaling networks. J Genet Genomics (2013) 40:367-74. doi:10.1016/j.jgg.2013.05.002

87. Rose NR, McDonough MA, King ONF, Kawamura A, Schofield CJ. Inhibition of 2-oxoglutarate dependent oxygenases. Chem Soc Rev (2011) 40:4364-97. doi:10.1039/c0cs00203h

88. Tsukada Y, Fang J, Erdjument-Bromage H, Warren ME, Borchers $\mathrm{CH}$, Tempst P, et al. Histone demethylation by a family of JmjC domain-containing proteins. Nature (2006) 439:811-6. doi:10.1038/nature04433

89. Shi D-Q, Ali I, Tang J, Yang W-C. New insights into 5hmC DNA modification: generation, distribution and function. Front Genet (2017) 8:100. doi:10.3389/ fgene.2017.00100

90. Li D, Guo B, Wu H, Tan L, Lu Q. TET family of dioxygenases: crucial roles and underlying mechanisms. Cytogenet Genome Res (2015) 146:171-80. doi: $10.1159 / 000438853$

91. Jin S-G, Wu X, Li AX, Pfeifer GP. Genomic mapping of 5hydroxymethylcytosine in the human brain. Nucleic Acids Res (2011) 39:5015-24. doi:10.1093/nar/gkr120

92. Hahn MA, Qiu R, Wu X, Li AX, Zhang H, Wang J, et al. Dynamics of 5-hydroxymethylcytosine and chromatin marks in Mammalian neurogenesis. Cell Rep (2013) 3:291-300. doi:10.1016/j.celrep.2013.01.011

93. Carey BW, Finley LWS, Cross JR, Allis CD, Thompson CB. Intracellular $\alpha$-ketoglutarate maintains the pluripotency of embryonic stem cells. Nature (2015) 518:413-6. doi:10.1038/nature13981

94. Yang H, Lin H, Xu H, Zhang L, Cheng L, Wen B, et al. TET-catalyzed 5methylcytosine hydroxylation is dynamically regulated by metabolites. Cell Res (2014) 24:1017-20. doi:10.1038/cr.2014.81

95. Cervera AM, Bayley J-P, Devilee P, McCreath KJ. Inhibition of succinate dehydrogenase dysregulates histone modification in mammalian cells. Mol Cancer (2009) 8:89. doi:10.1186/1476-4598-8-89

96. Xiao M, Yang H, Xu W, Ma S, Lin H, Zhu H, et al. Inhibition of $\alpha$-KGdependent histone and DNA demethylases by fumarate and succinate that are accumulated in mutations of FH and SDH tumor suppressors. Genes Dev (2012) 26:1326-38. doi:10.1101/gad.191056.112

97. Hoekstra AS, de Graaff MA, Briaire-de Bruijn IH, Ras C, Seifar RM, van Minderhout I, et al. Inactivation of SDH and FH cause loss of $5 \mathrm{hmC}$ and increased $\mathrm{H} 3 \mathrm{~K} 9 \mathrm{me} 3$ in paraganglioma/pheochromocytoma and smooth muscle tumors. Oncotarget (2015) 6:38777-88. doi:10.18632/oncotarget. 6091

98. Balss J, Meyer J, Mueller W, Korshunov A, Hartmann C, von Deimling A. Analysis of the IDH1 codon 132 mutation in brain tumors. Acta Neuropathol (2008) 116:597-602. doi:10.1007/s00401-008-0455-2

99. Amary MF, Damato S, Halai D, Eskandarpour M, Berisha F, Bonar F, et al. Ollier disease and Maffucci syndrome are caused by somatic mosaic mutations of IDH1 and IDH2. Nat Genet (2011) 43:1262-5. doi:10.1038/ ng.994

100. Moriya K, Kaneko MK, Liu X, Hosaka M, Fujishima F, Sakuma J, et al. IDH2 and TP53 mutations are correlated with gliomagenesis in a patient with Maffucci syndrome. Cancer Sci (2014) 105:359-62. doi:10.1111/ cas. 12337

101. Pansuriya TC, van Eijk R, d’Adamo P, van Ruler MAJH, Kuijjer ML, Oosting J, et al. Somatic mosaic IDH1 and IDH2 mutations are associated with enchondroma and spindle cell hemangioma in Ollier disease and Maffucci syndrome. Nat Genet (2011) 43:1256-61. doi:10.1038/ng.1004

102. Cairns RA, Iqbal J, Lemonnier F, Kucuk C, de Leval L, Jais J-P, et al. IDH2 mutations are frequent in angioimmunoblastic T-cell lymphoma. Blood (2012) 119:1901-3. doi:10.1182/blood-2011-11-391748
103. Cancer Genome Atlas Network. Comprehensive molecular characterization of human colon and rectal cancer. Nature (2012) 487:330-7. doi:10.1038/ nature11252

104. Dang L, White DW, Gross S, Bennett BD, Bittinger MA, Driggers EM, et al. Cancer-associated IDH1 mutations produce 2-hydroxyglutarate. Nature (2009) 462:739-44. doi:10.1038/nature08617

105. Ward PS, Patel J, Wise DR, Abdel-Wahab O, Bennett BD, Coller HA, et al. The common feature of leukemia-associated IDH1 and IDH2 mutations is a neomorphic enzyme activity converting alpha-ketoglutarate to 2-hydroxyglutarate. Cancer Cell (2010) 17:225-34. doi:10.1016/j.ccr.2010. 01.020

106. Figueroa ME, Abdel-Wahab O, Lu C, Ward PS, Patel J, Shih A, et al. Leukemic IDH1 and IDH2 mutations result in a hypermethylation phenotype, disrupt TET2 function, and impair hematopoietic differentiation. Cancer Cell (2010) 18:553-67. doi:10.1016/j.ccr.2010.11.015

107. Sasaki M, Knobbe CB, Munger JC, Lind EF, Brenner D, Brüstle A, et al. IDH1(R132H) mutation increases murine haematopoietic progenitors and alters epigenetics. Nature (2012) 488:656-9. doi:10.1038/nature11323

108. Lu C, Ward PS, Kapoor GS, Rohle D, Turcan S, Abdel-Wahab O, et al. IDH mutation impairs histone demethylation and results in a block to cell differentiation. Nature (2012) 483:474-8. doi:10.1038/nature10860

109. Xu W, Yang H, Liu Y, Yang Y, Wang P, Kim S-H, et al. Oncometabolite 2-hydroxyglutarate is a competitive inhibitor of $\alpha$-ketoglutarate-dependent dioxygenases. Cancer Cell (2011) 19:17-30. doi:10.1016/j.ccr.2010.12.014

110. Oldham WM, Clish CB, Yang Y, Loscalzo J. Hypoxia-mediated increases in L-2-hydroxyglutarate coordinate the metabolic response to reductive stress. Cell Metab (2015) 22:291-303. doi:10.1016/j.cmet.2015.06.021

111. Intlekofer AM, Dematteo RG, Venneti S, Finley LWS, Lu C, Judkins AR, et al. Hypoxia induces production of L-2-hydroxyglutarate. Cell Metab (2015) 22:304-11. doi:10.1016/j.cmet.2015.06.023

112. Leibundgut $\mathrm{M}$, Maier T, Jenni S, Ban N. The multienzyme architecture of eukaryotic fatty acid synthases. Curr Opin Struct Biol (2008) 18:714-25. doi:10.1016/j.sbi.2008.09.008

113. Katoh $\mathrm{Y}$, Ikura $\mathrm{T}$, Hoshikawa $\mathrm{Y}$, Tashiro $\mathrm{S}$, Ito $\mathrm{T}$, Ohta $\mathrm{M}$, et al. Methionine adenosyltransferase II serves as a transcriptional corepressor of Maf oncoprotein. Mol Cell (2011) 41:554-66. doi:10.1016/j.molcel.2011. 02.018

114. Karner CM, Esen E, Chen J, Hsu F-F, Turk J, Long F. Wnt protein signaling reduces nuclear acetyl-CoA levels to suppress gene expression during osteoblast differentiation. J Biol Chem (2016) 291:13028-39. doi:10.1074/ jbc.M115.708578

115. Nagaraj R, Sharpley MS, Chi F, Braas D, Zhou Y, Kim R, et al. Nuclear localization of mitochondrial TCA cycle enzymes as a critical step in mammalian zygotic genome activation. Cell (2017) 168:210-23.e11. doi:10.1016/j.cell.2016.12.026

116. Mews P, Donahue G, Drake AM, Luczak V, Abel T, Berger SL. AcetylCoA synthetase regulates histone acetylation and hippocampal memory. Nature (2017) 546:381-6. doi:10.1038/nature22405

117. Zhang T, Berrocal JG, Frizzell KM, Gamble MJ, DuMond ME, Krishnakumar R, et al. Enzymes in the NAD+ salvage pathway regulate SIRT1 activity at target gene promoters. J Biol Chem (2009) 284:20408-17. doi:10.1074/jbc. M109.016469

118. Zhang T, Berrocal JG, Yao J, DuMond ME, Krishnakumar R, Ruhl DD, et al. Regulation of poly(ADP-ribose) polymerase-1-dependent gene expression through promoter-directed recruitment of a nuclear NAD+ synthase. J Biol Chem (2012) 287:12405-16. doi:10.1074/jbc.M111.304469

Conflict of Interest Statement: The authors declare that the research was conducted in the absence of any commercial or financial relationships that could be construed as a potential conflict of interest.

Copyright $\odot 2017$ Rabhi, Hannou, Froguel and Annicotte. This is an open-access article distributed under the terms of the Creative Commons Attribution License (CC BY). The use, distribution or reproduction in other forums is permitted, provided the original author(s) or licensor are credited and that the original publication in this journal is cited, in accordance with accepted academic practice. No use, distribution or reproduction is permitted which does not comply with these terms. 